\section{MATERIALES PARA UNA INVESTIGACIÓN FENOMENOLÓGICA SOBRE EL DINERO}

\author{
Joan González \\ Universitat de Barcelona
}

\begin{abstract}
In this paper we intend to lay the grounds for a Phenomenology of money. We start from the pre-theoretical comprehension of money as an "entity for", that is to say, as a tool. Within this pre-theoretical comprehension, money is always understood according to its teleology (money is always "something to buy with"). Also, in this pre-theoretical framework money is hardly ever defined as "something to sell with", or as "something being the result of my work". Thus, in our daily experience the being of money becomes undistinguishable with the act of purchasing, which in turn underlines the deeply projective nature of money's essence. In order to grasp this projective quality, we will have to develop a phenomenlogy of the purchasing act. "To purchase" is "to get something by means of money". But, what is this thing that we get anyway? Whatever it is, it has a distinctive character: it is a merchandise. Through the appropiate phenomenologial descriptions, we will try to show how the description of the spatiality and temporality of the merchandise is essential to understand the effects of money upon the spatiality and temporality of the surrounding world.
\end{abstract}

KEY WORDS: Phenomenology of money, theory of money, merchandise, credit.

La perspectiva que tomaremos para concretar la vigencia de la fenomenología será directa. Tomaremos una problemática concreta que ha rebrotado con fuerza en las últimas décadas respecto a la más práctica de las ciencias, la teoría económica, y mostraremos las posibilidades que tiene un tratamiento fenomenológico de los presupuestos que esta teoría económica está llevando a cabo en sus planteamientos.

\section{EL RETORNO DE LA CUESTIÓN: ¿QUÉ ES EL DINERO?}

En las últimas décadas ha rebrotado en el terreno de debate de las teorías económicas la cuestión sobre la de-

\section{MATERIALS FOR A PHENOMENOLOGICAL INVESTIGATION ABOUT THE MONEY}

RESUMEN: En nuestra exposición pretendemos hacer una aportación a la fundamentación de una fenomenología del dinero. Se parte del hecho de la comprensión preteórica del dinero como un "ente para", es decir, como un útil. En esta comprensión preteórica, el dinero es entendido siempre desde su teleología: el dinero es [algo que es] para comprar. Difícilmente se define el dinero desde la actitud preteórica como "algo para vender" o como "el resultado del esfuerzo de mi trabajo". El ser del dinero deviene, desde su vivencia cotidiana, inseparable del acto de compra, remarcando la naturaleza profundamente proyectiva de su esencia. Para captar esta naturaleza proyectiva del dinero, será necesario llevar a cabo una fenomenología del acto de compra. "Comprar" es obtener algo con dinero. Pero, ¿cómo es la cosa adquirida? No es una cosa cualquiera: es una mercancía. En descripciones fenomenológicas sucesivas se intentará mostrar cómo la descripción de la espacialidad y la temporalidad de la mercancia es esencial para comprender aquello que el dinero lleva a cabo con la espacialidad y temporalidad del mundo circundante.

PALABRAS CLAVE: Fenomenología del dinero, teoría del dinero, mercancía, crédito.

finición del dinero'. En buena medida, la cuestión de la definición del dinero había sido enterrada desde que los manuales de teoría económica se conformaran con una definición puramente funcional: el dinero es cualquier cosa que asume las funciones de unidad de cuenta, medio de pago y reserva de valor ${ }^{2}$. Esta definición funcional, que sigue figurando como la definición "oficial" en la práctica mayoría de los manuales de economía, ha entrado en crisis con el cuestionamiento que la escuela poskeynesiana ha llevado a cabo del concepto de "dinero exógeno". Vamos a intentar resumir muchísimo esta entrada en crisis de la definición funcional del dinero por parte de los teóricos poskeynesianos, para sentar las bases que un enfoque fenomenológico podría aportar a la problemática. En principio, definir el dinero como "cualquier cosa" que reúna esas cuatro funciones, indica que se comprende el dinero 
como una "cosa"3. "Cualquier cosa" es, al menos, una cosa. Lo que dice la definición es que, en un momento dado, no importa que sea ésta o aquélla, pero se presupone que el dinero es "algo" que sirve para $X, Y$, etc. ${ }^{4}$.

Que el dinero sea una cosa indica que esta cosa es separada de las otras para ejercer una nueva función. Supongamos que escogemos la plata (en función de algunas condiciones físicas observables, como su durabilidad, divisibilidad, portabilidad, etc.) como la cosa que será utilizada como dinero. A partir del momento en el que escogemos la plata, el uso que estamos dando a la plata es un uso totalmente diferente al que le damos a la plata cuando con ella fundimos armaduras $u$ otros utensilios. Es un uso diferente, pero es un uso. Es "otro" uso, distinto de su uso habitual. La plata con la que trabaja el herrero es precomprendida inmediatamente por él como un "ente para" hacer armaduras. La plata de las monedas con las cuales el herrero va al mercado a cambiar su armadura por, vamos a poner un ejemplo, caballos, es precomprendida inmediatamente por él como un "ente para" intercambiar productos $^{5}$. Esta forma de presentarse las cosas en tanto que dominadas por esta estructura del "ser-para" es, según una famosa caracterización llevada a cabo por Heidegger, la forma de presentarse de las cosas en la cotidianidad más inmediata, regular y prereflexiva ${ }^{6}$ : el dinero se presenta en la cotidianidad inmediata y regular como un "ente-para"; como un "útil"7. ¿Cuál es el "para qué" del dinero? El "para qué" del dinero es, en su concepción exógena, facilitar los intercambios de mercancías. Para facilitar los intercambios entre mercancías, se segrega una mercancía del sistema de mercancias que permite expresar el valor "simbólico" de las otras dos en un lenguaje nuevo. La esencia de este dinero, así considerado, es la utilidad. El dinero es introducido desde fuera de las relaciones económicas fundamentales (relaciones de producción) para facilitarlas; el dinero, en una metáfora habitualmente utilizada, es un lubricante de los intercambios ${ }^{8}$. Esto es lo que entendemos como dinero exógeno: algo (sea una mercancía o no, aunque hay una tendencia interna a la tesis de la exogeneidad a fijar una génesis en el dinero-mercancía) introducido externamente a unas relaciones de intercambio que ya se están produciendo, y que se vienen a mejorar y a facilitar mediante su introducción. Evidentemente, el enfoque de los economistas neoclásicos apuntaba a esta tesis de la exogeneidad del dinero, al intentar por todos los medios determinar de qué manera el aumento o la reducción de la masa monetaria afecta a las relaciones de intercambio. Según esta concepción, es la cantidad disponible de materia de la que está hecho el dinero (en el caso de dinero-mercancía simple) o la política del instituto de emisión (en el caso de dinero simbólico) lo que puede determinar de manera esencial la evolución de los precios. Esta concepción estaba en la base de la teoría cuantitativa del dinero ya en Locke o Hume, pero sigue siendo todavía la base de la nueva concepción cuantitativa del dinero de Milton Friedman, por poner un ejemplo, al reconocer una oferta de dinero independiente de la demanda9.

Esta tesis comienza a ser cuestionada por los teóricos poskeynesianos cuando se comprueba que, en el caso del dinero bancario, no se respeta el principio de exogeneidad. Si el dinero bancario respetara el principio de exogeneidad, su existencia como stock sería independiente de la demanda. El dinero sería administrado desde fuera (en este caso, desde el banco central emisor a los bancos comerciales, que crearían los depósitos), de manera que en principio la función de su oferta sería una función independiente, es decir, no determinada por la demanda. La independencia de la oferta de dinero es un elemento esencial de la tesis exógena. Ahora bien, la independencia de la oferta de dinero sólo puede ser fijada sobre la base de entender el dinero como una cosa, como un stock, ya que éste existe previamente sin necesidad de ser prestado a nadie. Esto no tiene lugar en el caso del dinero bancario. El dinero bancario es un crédito de un depositante a un banco, que se forma en contrapartida de un crédito concedido por el banco a un prestatario. La oferta de dinero es pues indisociable de la demanda de dinero formulada por los prestatarios, con lo cual la hipótesis de la exogeneidad queda cuestionada: "Así, la cantidad de dinero existente no da ninguna indicación sobre el volumen corriente del crédito. Dado que la oferta de dinero de crédito se nutre del desarrollo del crédito, la oferta ya no es independiente de la demanda. El stock de dinero bancario es totalmente determinado por la demanda de crédito por parte de los prestatarios. Al contrario que el dinero-mercancía, el dinero bancario no existe si no es simultáneamente ofrecido y demandado. Creado en una operación de crédito, no existe a menos que sea prestado"mo.

El problema del cuestionamiento de la tesis exógena del dinero, que conlleva el cuestionamiento de las teorías cuantitativas del dinero, se ha centralizado por parte de 
los propios teóricos poskeynesianos como el de una desatención a la cuestión de la naturaleza del dinero; a la cuestión de su definición ${ }^{11}$. Habría un olvido del fundamento ontológico último del dinero en los presupuestos de las teorias cuantitativas del dinero. Con todo, aunque los poskeynesianos vuelvan a subrayar un resurgimiento de la cuestión ontológica del dinero, a menudo sus concepciones se embarrancan también en contradicciones internas $^{12}$. ¿Puede un enfoque fenomenológico sobre la cuestión de la esencia del dinero aportar algo a la problemática? Si, como pensaba Husserl en los arrebatos más optimistas de los inicios de su proyecto, corresponde a la fenomenología la tarea de una fundamentación de las ciencias $^{13}$, cabe intentar, no ya esa fundamentación, sino, desde el realismo austero al que lleva nuestra situación actual de descomposición del diálogo entre la filosofía y las ciencias, una simple aproximación a la cuestión desde una metodología fenomenológica. El proyecto husserliano de una fundamentación de las ciencias en la fenomenología, quizás uno de los elementos más caducos de su propuesta, puede ser, como a él le gustaría decir sin duda, "reactivado", desde la posición más humilde de intentar establecer un diálogo abierto entre los presupuestos de la teoría económica y la metodología fenomenológica. La posibilidad de ese diálogo sería, sin duda, una de las demostraciones más activas de la vigencia del pensamiento fenomenológico.

\section{DesCripCión FENOMENOLÓgICA deL ACtO DE COMPRA: EL DINERO-ESPACIO}

Es imprescindible comenzar con algunas precisiones metodológicas. La fenomenología es un método, simplificando necesariamente muchísimo en este momento, consistente en considerar "todo lo que se nos brinda originariamente - por decirlo así, en su realidad corpórea- en la 'intuición' simplemente como se da, pero también sólo dentro de los límites en que se $\mathrm{da}^{\prime \prime 4}$. Esto presupone que hay un darse originario de las cosas; un darse a la intuición en el cual estas cosas se manifiestan en su ser. La proclama de la intución de lo originariamente dado se supone como antídoto contra la invasión en la vida teórica de objetividades presupuestas no fundadas que habrían ganado carta de naturaleza. Las construcciones científicas se habrian independizado del mundo de la vida que en algún momento les dio su fundamento, y habrian usurpado el fundamento último de la comprensión de la realidad. Frente a esto, la fenomenología propone subrayar el retorno al mundo de la vida en el cual las cosas nos son dadas como lo que efectivamente son. No hay atisbo alguno, en la posición de Husserl, de anticientificidad; todo lo contrario, la incorporación de la temática del mundo de la vida propone fundamentar las ciencias, el funcionamiento racional de las cuales no es nunca cuestionado. Se pretende volver a las ciencias al redil de la cientificidad con mayúsculas, el origen de la cual es siempre fenomenológico. Esta metodología presupone considerar el dinero tal y como se da originariamente a la intuición, y tan sólo dentro de los límites en que se $\mathrm{da}^{15}$. Pero, ¿cómo se da el dinero a la intuición? ¿Es posible una donación originaria del dinero? Desde la metodología de la economía, se diría enseguida que la consideración respecto a cómo el dinero se da en la intuición no tiene ningún efecto sobre los principios que rigen el funcionamento real del dinero. La visión ingenua y de sentido común del dinero está plagada de prejuicios y de consideraciones que son simplemente erróneas, y esto es comprobable desde los axiomas de la teoría. Pero cuando la cuestión es la naturaleza del dinero; cuando la cuestión es "qué es" el dinero, tal y como se plantean los nuevos debates entre una naturaleza exógena o endógena del dinero, ¿cabe considerar cómo es vivido el dinero en el mundo de la vida, cómo es vivido en nuestra cotidianidad preteórica? ¿Qué es el dinero? No preguntemos ahora a los economistas, ni a los filósofos, ni a los teóricos del derecho. Preguntemos a cualquiera que no esté pensando en su naturaleza. La coincidencia es abrumadora: "Es algo que sirve para comprar". Es una respuesta evidente. Tan evidente que no parece que podamos hacer nada con ella. Y sin embargo, aquí "evidente" no es sinónimo de "obvia". Nadie responde "unos papeles de celulosa rectangulares, de diversos colores según su valor", o "aquello que obtengo como fruto de mi trabajo", y no obstante, el dinero es también esto. Nadie responde que "el dinero es algo que sirve para vender", y no obstante, el dinero es también esto. El concepto de "intercambio", como concepto más abstracto que recoge tanto al comprador como al vendedor, muy difícilmente hará su aparición cuando nos referimos a la comprensión preteórica del dinero. El dinero es "algo para comprar".

¿Qué es "comprar"? "Comprar" es, según el diccionario de la $R A E$, "obtener algo con dinero". Hay aquí una aparente

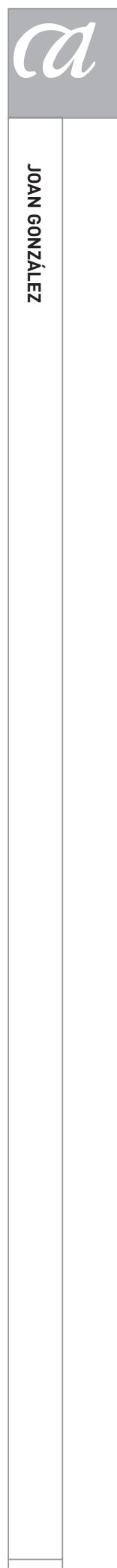


circularidad: el dinero es algo que es para comprar, y comprar es una forma de obtener algo mediante dinero. Para salir del círculo, debemos describir esta forma de obtener algo en contraste con otras formas de obtener algo que no sean el dinero. Porque no todo "obtener algo" se hace mediante el dinero. El campesino obtiene de la lluvia beneficios respecto a su actividad económica (y deja de obtenerlos en su ausencia), y el campesino no ha pagado nada por la lluvia. Un regalo es algo no obtenido mediante el dinero. Y serían posibles bastantes ejemplos más. En cambio, ¿qué caracteriza la obtención de algo mediante dinero? Lo obtenido mediante dinero debe ser descrito en su especificidad para poder obtener la esencia de lo que es un acto de compra.

Cuando para obtener algo necesitamos de la mediación de dinero, decimos de este algo que es una "mercancía". Mercancía designa un modo de ser de una cosa, determinado precisamente porque el dinero es el acceso necesario para su obtención. La mercancía es la cosa cuando para acceder a ella necesito dinero. Pero con esto no estamos dando, ni mucho menos, una definición de la mercancía: la definición de la mercancía la tendremos cuando determinemos por qué su obtención sólo es posible mediante el dinero. Es decir, requerirá de la descripción del modo de ser "mercancía" como tal. Una flor cogida en un paseo campestre no tiene el mismo modo de ser que la misma flor en una floristería de la ciudad. Es obvio que nos estamos refiriendo al mismo ente, pero este mismo ente aparece según dos modos de ser distintos.

¿Cómo es la cosa "mercancía"? Para empezar, la cosa "mercancia" se caracteriza porque está ahi "delante". Está ex-puesta; puesta "fuera". ¿Fuera de qué? Fuera del espacio de las cosas "a la mano". La mercancía no está "a la mano"; no se me ofrece en la disponibilidad inmediata de las otras cosas que me rodean. Con "disponibilidad" no nos referimos aquí a "distancia física". Cuando hablamos de que la mercancía no está "a la mano", no nos referimos a que no esté a mi alcance "físicamente"; no nos referimos ni siquiera a que la mercancía esté separada de mi cuerpo mediante una distancia física o mediante el obstáculo de otro ente (un escaparate, por ejemplo). El modo de ser de la mercancía no es tampoco "a la mano" cuando en una tienda no hay ninguna distancia ni separación física entre yo y la cosa; la mercancía conserva su carácter de mercancía, en tanto que ex-puesta, en las tiendas en las cuales yo camino "entre" ellas; en aquellas tiendas en las cuales yo me muevo entre ellas y están constantemente a mi alcance (a mi tacto, a mi proximidad, incluso al hecho de "probarla"). En estos casos, no pierde la cosa "mercancía" su carácter de ser en tanto que mercancía; por mucha proximidad física que tenga respecto de mí la mercancía, la mercancía sigue sin estar "a la mano", sino que se presenta en todo momento como estando "ahí enfrente" ${ }^{16}$. En cambio, en el espacio de la misma tienda, hay cosas que no tienen el modo de ser de la mercancía y que, no obstante, están "a la mano", independientemente también de la distancia física que estos objetos tengan respecto a mí. Un cenicero o una papelera (en el bien entendido de que no se presentan como artículos a la venta en la tienda) son cosas "a la mano". Su ser "a la mano" no viene determinado porque estos objetos estén "a este lado" del escaparate, si es que hubiera escaparate; un reloj o un espejo (en el bien entendido de que no son artículos a la venta) son cosas "a la mano" incluso estando al otro lado del escaparate, y alejadas de mí "físicamente". El modo de ser de la mercancía destaca pues, en primer lugar, porque su espacialidad no es la espacialidad propia del ente "a la mano". Cabe señalar también, en este momento del análisis, que la distinción entre el modo de ser de la mercancía y el modo de ser de otra cosa que no es mercancía no tiene que ver tampoco, por lo recientemente señalado, con la propiedad de la cosa, en el sentido de que le pertenecería a toda cosa que no fuera todavía "mía" el modo de ser de la mercancía. Las cosas que son mercancías no son, efectivamente, "mías"; no son todavía de mi propiedad, pero no es este hecho el que hace que la cosa se manifieste como mercancía, dado que el cenicero o la papelera de la tienda no son tampoco de mi propiedad $y_{\text {, }}$ no obstante, no se me manifiestan bajo el modo de ser de la mercancía; de la misma manera, un banco de la calle en el cual me siento después de un largo paseo o un árbol del campo bajo la sombra del cual me cobijo del sol no son tampoco objetos de mi propiedad, y no obstante, no se me manifiestan como mercancias. Por tanto, el hecho de que la cosa no sea de mi propiedad es una condición necesaria, pero no suficiente, para determinar el modo de ser de la mercancía.

La cosa que se me aparece como mercancía está ahí expuesta. La ex-posición señala el carácter específico de la espacialidad de la mercancía. La espacialidad de la mercancía (la ex-posición) no es la espacialidad de lo "a la 
mano" (Zuhanden). La espacialidad de lo "a la mano" es una espacialidad que se constituye en una cercanía que no se mide en centímetros. El cenicero está ahí a mi alcance; se me ofrece inmediatamente en su "para qué". El reloj, al otro lado del escaparate, no está a mi alcance, por lo que a centímetros se refiere, pero está inmediatamente a mi alcance por lo que a su utilidad se refiere; está inmediatamente a mi alcance cuando percibo que se me está haciendo tarde. El espejo en el cual me veo, que está "ahí mismo" aunque esté separado de mi cuerpo por bastante distancia, está inmediatamente a mi alcance cuando me doy cuenta, casi como quien no quiere la cosa, de que estoy despeinado. El espejo está a mi alcance (y "alcance", reiteramos, no dice aquí nada de distancia física mesurable cuando alargo el brazo), cuando decido arreglarme un poco el pelo antes de seguir mirando entre las mercancías. Cenicero, papelera, reloj, espejo, son entes "a la mano", independientemente de la distancia que los separe de mi cuerpo. Por tanto, con la expresión "a la mano" no designamos un atributo más o menos objetivo de las cosas, sino una modalidad del ser de los entes. De la misma manera, con la "ex-posición"; con el "estar ahí enfrente" (Vorhanden) de las cosas que llamamos mercancías, no designamos tampoco un atributo más o menos objetivo de las cosas, sino también una modalidad del ser de los entes. Las expresiones "a la mano" o "ahí enfrente" no son más que expresiones metafóricas con las cuales penosamente intentamos abrirnos camino, a partir del lenguaje, hacia los fenómenos que precisan ser dichos. Así, no debe entenderse en lo "ahí enfrente" una especial potencia de la "percepción visual", frente a una especial potencia de lo "táctil-instrumental" en el modo de ser de lo "a la mano". Las modalidades del ser aquí presentadas no son deducibles a partir de teoría de la percepción alguna, ni de cualquier teoría de la atención. Las modalidades del ser no tienen nada que ver con los "sentidos" a través de los cuales se perciben las cosas. En cierto sentido, podríamos afirmar que la distinción entre "ser a la mano" y "ser ahí enfrente" es transversal a todos los sentidos, y tiene poco que ver con la preponderancia de un sentido perceptivo sobre los demás. De ahí la importancia de los ejemplos del espejo y el reloj, que son cosas "a la mano" cuya comprensión se da a través de la vista sin que hablemos, en ningún caso, de ex-posición. La mercancía no es mercancía porque esté ex-puesta "para ser vista"; al contrario, mi aproximación a ella mediante la visión ya se da condicionada porque la cosa se me presenta bajo las condiciones de aparición de la mercancía. El reloj de la tienda está colocado (que no ex-puesto) para ser visto, y no obstante, el reloj es una cosa "a la mano", no una mercancía. No es una especial atención de mi percepción visual; no es ninguna atrofia de lo visual respecto a lo "manual-operacional", lo que hace de una cosa una mercancía. Por tanto, cabe aquí dejar de lado cualquier intento de deducción de las modalidades del ser que estamos describiendo a partir de una "teoría de los sentidos" o de una "teoría de la percepción".

Por otro lado, la mercancía se presenta según el modo de ser de lo "ex-puesto", de lo "ahí enfrente"; pero no todas las cosas que se presentan según el modo de ser de lo "ahí enfrente" son mercancías. El modo de ser de la mercancía es una clase dentro de las cosas que son según el modo de ser de lo "ahí enfrente", pero no la única. La mercancía es "ahí enfrente" en el modo de la "ex-posición". La "ex-posición" es pues tan sólo una manera entre otras de "ser ahi-enfrente". La no familiaridad (Unvertrautheit) o la novedad (Neuheit) suponen algunas otras formas de modalización de una cosa "ahí enfrente" ${ }^{17}$. En estos modos de ser de la cosa como "ahí enfrente", el "ser enfrente" de la cosa está basado, en algún sentido, en la "no familiaridad" en el trato respecto de la cosa, que se define siempre y en todo momento a partir de la familiaridad con un ámbito de cosas cotidianamente constituido que esta nueva modalidad de presentación viene a romper. En cambio, en la "ex-posición" como modalidad del "ahí-enfrente" propia de la mercancía, el carácter de "ser enfrente" de la cosa no proviene de una falta en el habérselas con la cosa; no proviene de una insuficiencia del trato, o de una presentación que irrumpe en la "totalidad respeccional" (Bewandtnisganzheit) en la cual se encuentran las cosas de mi cotidianidad" ${ }^{18}$. Supone una especificidad de la "ex-posición" como modo de "ser enfrente" propio de la mercancía el hecho de que en este caso lo "enfrente" no se constituye desde una ruptura de la espacialidad de lo "a la mano", sino desde una estricta continuidad ( $y$, diríamos incluso, interpenetrabilidad) respecto a la totalidad respeccional de las cosas "a la mano". Lo no familiar o lo nuevo irrumpen en la totalidad respeccional de las cosas cotidianas "a la mano", y de alguna manera resaltan respecto al fondo de la cotidianidad; el "ser enfrente" de lo no familiar o de lo nuevo se confunde, de alguna manera, con este carácter "irruptivo"; es decididamente difícil separar dónde comienza el carácter de la irrupción con el carácter de "ser enfrente" de la cosa que se manifiesta según ese modo de ser. En cambio, en el caso de la mercancía, caminamos na-

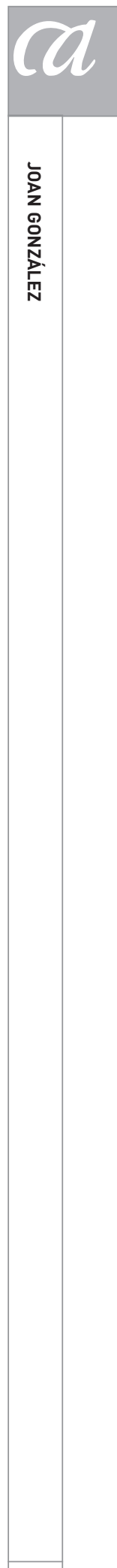

293 
turalmente entre ellas, como si formaran parte integrante de nuestra totalidad respeccional, y no obstante, nuestro trato con ellas nunca es un trato como con cualquier otro ente "a la mano".

La espacialidad de esa zona que Ilamamos "tienda" se constituye pues como una espacialidad híbrida. Yo me muevo, me desplazo, deambulo entre mercancias que, en cierto sentido, constituyen mi espacio circundante; las mercancias son, en la zona de la tienda, el ente que me viene inmediatamente al encuentro; como entes que me vienen inmediatamente al encuentro, no son extraños, ni son, tampoco, no-familiares; con todo, son "ahí enfrente" en tanto que ex-puestos; por muy normalmente y cotidianamente que se constituyan en mi deambular a través de ellos, en todo momento se me manifiestan como "alejados", o según una fórmula posible, a pesar de su aparente complejidad, "des-alejados en su alejamiento"19. Este alejamiento consiste en su propia espacialidad: están sobre los maniquís, en cajas, alineadas sobre estanterías, encerradas en escaparates... La ex-posición saca a la cosa de su lugar (Platz) ${ }^{20}$ y le constituye uno nuevo; este nuevo lugar sólo le pertenece a la cosa dentro de la zona de la tienda. Pasear por una tienda quiere decir: pasear entre cosas des-colocadas; pasear entre cosas cuyo lugar es, provisionalmente, estar "fuera de lugar". El lugar de la camisa no es el maniquí, sino el cuerpo humano; el lugar del coche no es el escaparate del concesionario, sino la carretera o el garaje. El coche, dentro de los límites del escaparate del concesionario, no tiene espacio para correr. La comida, alineada sobre la estantería, no tiene a su lado ninguna mesa en la que poder comer; no hay platos ni vasos ni buena compañía; tampoco hay cerca fogón alguno en el que poder cocinar. Esta percepción de la mercancía como "des-colocada", como fuera del lugar en el que podría ser "a la mano" (connatural a la ex-posición), señala el carácter peculiar de su espacialidad híbrida ${ }^{21}$ : la mercancía está en un espacio que no es "a la mano", pero que es un espacio constituido para que las cosas puedan llegar a ser "a la mano" en la totalidad respeccional de las cosas de mi mundo circundante cotidiano concreto. A partir de esta última consideración, puede llevarse a cabo una determinación ontológica del verbo "comprar" que supere su mera determinación óntica como "obtener algo con dinero". "Comprar" es "obtener algo con dinero" tan sólo desde la perspectiva preanalítica que no ha determinado todavía los contenidos descriptivos específicos de este "algo" que es obtenido mediante el dinero. Este "algo" que se obtiene mediante el dinero es la "mercancía". El contenido fenomenológico descriptivo de la mercancía ha sido descrito teniendo en cuenta la espacialidad de su modo de manifestación. La elección del eje de la espacialidad a la hora de describir la mercancia no ha sido una elección arbitraria, como si pudiéramos haber escogido cualquier otro eje para describir la mercancía. El modo de ser de la mercancía está directamente vinculado a la experiencia humana de la espacialidad ${ }^{22}$. Desde esta experiencia, cuya descripción ha sido esbozada con anterioridad, puede determinarse el contenido ontológico de la palabra "comprar": "Comprar" es cambiar, mediante un acto de la voluntad, la modalidad de ser de una cosa; concretamente, es convertir la cosa ex-puesta en cosa "a la mano"; es, por tanto, integrar una cosa a la totalidad respeccional de cosas que configuran mi mundo circundante cotidiano. En este sentido, es convertir lo ex-puesto en colocado; y colocado en mi mundo circundante cotidiano. Desde la definición fenomenológica de "mundo", vinculada a la totalidad de remisiones y a la totalidad respeccional, puede decirse que "comprar" es ampliar el mundo. Es absolutamente necesario ser cautos con cualquier juicio de valor respecto a esta última afirmación: su sentido es absolutamente técnico y específicamente vinculado a la definición fenomenológica de mundo como "totalidad de remisiones" y "totalidad respeccional"23. Ésa camisa azul no estaba antes en el horizonte de des-alejamiento de las cosas de mi mundo circundante cotidiano; pero después de comprarla, pasa a formar parte de él. Es un elemento más de mi totalidad respeccional cotidiana. Cabe vaciar la correspondencia establecida entre la acción de "comprar" y la "ampliación del mundo" (fenomenológicamente comprendido) de cualquier contenido de valor, ya sea éste crítico o apologético: su contenido es, en el orden de nuestras investigaciones, meramente descriptivo. En este sentido, la palabra "ampliación" habla simplemente de una mayor complicación cuantitativa (en algunos casos cualitativa, como cuando compro algo que implica una estructura de remisiones que nunca se había dado antes: eso es lo nuevo, como cuando compro un ordenador por primera vez) en las remisiones y conformidades entre las cosas de mi mundo circundante y yo mismo. Un número mayor de camisas en un armario implica, desde una perspectiva meramente cuantitativa, una mayor cantidad de remisiones entre los entes de mi mundo circundante (por ejemplo, mayores posibilidades de combinación entre los pantalones y las camisas según la diversidad de sus colo- 
res). Un exprimidor de naranjas implica la posibilidad de una remisión con las naranjas de la cesta que, respecto a mí mismo, me presenta la posibilidad de tomar zumos naturales (en este caso, la remisión es cualitativa). Esto son posibilidades de remisión y de conformidad entre las cosas de mi mundo circundante "a la mano" y yo mismo que no se dan de no poseer estas cosas a mi alrededor en su modo de ser "a la mano". En ningún caso, la existencia de estas posibilidades implica que estas remisiones, cuantitativamente amplias, encuentren un cumplimiento. Mucha gente tiene un exprimidor de naranjas acumulando polvo en un trastero de la cocina porque es más fácil comprar un zumo prefabricado. Puede pasar que haya muchas combinaciones entre camisas y pantalones que nunca se lleguen a efectuar en un momento dado como una remisión fáctica llegando a tener conformidad conmigo mismo. Del hecho de la ampliación cuantitativa de la conectividad de las remisiones, y la conformidad de estas remisiones respecto a mí, no se deduce en ningún momento una evaluación positiva del acto de compra como tal. Reiteramos que nos movemos, de momento, en un ámbito puramente descriptivo. Pero negar el hecho de que, en la vivencia del acto de compra, subyace una vivencia de "ampliación del mundo", entendida ésta como una ampliación cuantitativa de las cosas que me vienen inmediatamente al encuentro en el modo de lo "a la mano", y por tanto, una ampliación cuantitativa de las relaciones de conformidad de las cosas que me vienen al encuentro en mi cotidianidad inmediata, sería negar el aspecto de fascinación que el acto de compra parece ejercer sobre los seres humanos. Los seres humanos quieren "tener cosas", no porque sean avariciosos o porque confundan, como afirman muchos discursos más o menos angélicos, el "ser" con el "tener"24, sino porque "tener cosas" implica que desde el ámbito del ente que me viene inmediatamente al encuentro como "a la mano" se establecen nuevas posibilidades de acción en el mundo. Esto es un hecho descriptivo puro, no susceptible (todavía) de evaluación o valoración. Cosas que me rodean (e incluso a veces casi me asaltan) y que no pueden ser incorporadas a la totalidad de remisiones y a la totalidad respectiva de mi mundo cotidiano circundante por su modo de manifestación pueden pasar a ser incorporadas a mi mundanidad cotidiana mediante un acto de compra: éste es el sentido del dinero. El dinero tiene como finalidad llevar a cabo esta transmutación; esta "conversión" en la modalidad del ser. El dinero modaliza el ser de los entes en su manifestación ${ }^{25}$.

\section{TRANSICIÓN: DEL DINERO-ESPACIO AL DINERO- TIEMPO. El CRÉDITO}

Las descripciones anteriores del dinero están basadas en la experiencia espacial de lo que el dinero lleva a cabo, que es la primera que se manifiesta a la percepción de la vida cotidiana. Es a esta experiencia a la que pueden remontarse todos los intentos genéticos de explicar el origen del dinero a partir del dinero-mercancía: el dinero lleva a cabo una profunda transmutación en la comprensión del espacio del mundo. De estas descripciones entendemos enseguida que lo primero a lo que el significado íntimo del dinero está ligado es a la comprensión del mundo, en el caso descrito hasta aquí, a la espacialidad del mundo. Toda tesis sobre la exogeneidad del dinero está fundamentada, por muy inconsciente que sea de sus fundamentos ontológicos propios, en la comprensión del mundo como el ámbito los entes del cual pueden modalizarse mediante el dinero. Esto es mal expresado en el lenguaje teórico de la economía con expresiones como "intercambio", "trueque", etc. Evidentemente, los elementos de esta concepción del dinero, que llamaremos "dinero-espacio", también son susceptibles de una génesis. La espacialidad de la ex-posición es susceptible de una fenomenología genética; incluso de una historia genética. Una buena aproximación a ésta sería la historia de la palabra "mercado", como la palabra que designa el espacio en el cual se genera la ex-posición, y su diferenciación respecto al otro concepto de "mercado", el puramente económico, entendido como un mecanismo creador de precios basado en la fluctuación libre de la oferta y la demanda ${ }^{26}$. En todo caso, cabe pensar en una génesis del mercado, y podemos pensar en una realidad previa a que la espacialidad de la ex-posición se diera como tal. Con todo, no es éste el lugar para estas investigaciones.

¿Cuál es la fuente fenomenológica de la endogeneidad del dinero? Será una vivencia de la temporalidad del dinero. Esto conlleva una interpretación fenomenológica del crédito. Si somos capaces de ofrecer una descripción fenomenológica de la temporalidad del dinero, sentariamos las bases para una teoría fenomenológica unificada sobre la cuestión entre la exogeneidad y la endogeneidad del dinero. Por problemas de espacio, ofreceremos tan sólo un esbozo de la descripción fenomenológica del vínculo entre el dinero y el tiempo.

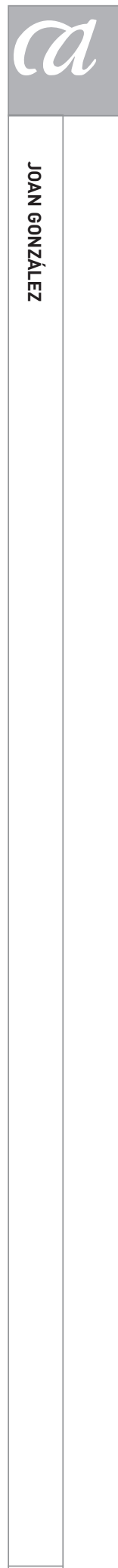




\section{El dinero-tiempo. Crédito y mundo}

El fundamento de la teoría exógena del dinero descansa en su comprensión como un "útil" (Zeug). El dinero es vivido en la conciencia como un ente cuya utilidad es poder incorporar otras cosas a mi mundo-entorno ${ }^{27}$. Esta función del dinero no es neutral respecto a la temporalidad. Es un elemento de esta utilidad de manera esencial el hecho de que el tiempo en el cual estas cosas son incorporables a mi mundo-entorno disminuye mediante el uso del dinero. La espacialidad de la ex-posición y el ahorro de tiempo tienen un vínculo directo: lo ex-puesto me es "acercado" ahorrando el tiempo que se invertiría en su incorporación ${ }^{28}$. Que el tiempo es dinero en este sentido es algo sabido y observado desde antiguo, ya desde las famosas sentencias de Benjamin Franklin, que Max Weber consideraba como uno de los núcleos del "espíritu del capitalismo"29. Pero este sentido en el cual el tiempo es dinero está en todo momento supeditado al dinero-espacio, al dinero como modalizador de la espacialidad de los entes, tal y como nos ha aparecido hasta aquí. El que mejor ha visto esta vinculación entre tiempo y espacio en la subordinación del primero al segundo ha sido Simmel: "Cuando investigamos la función del dinero en esta diferenciación, lo primero que se observa es que éste está en relación con la distancia espacial entre el sujeto y su propiedad. El accionista, que nada tiene que ver con la dirección de la empresa; el acreedor, que jamás ha pisado la tierra que se le adeuda como fianza; el terrateniente, que ha dado en arriendo sus tierras; todas estas personas han confiado sus posesiones a una empresa puramente mecánica, cuyos frutos cosechan, pero en la que no tienen nada que hacer en y para sí. Y ello solamente es posible gracias al dinero" ${ }^{30}$. Simmel observa el papel de separación que lleva a cabo el dinero entre el origen y el final de los procesos económicos; el dinero es el agente fundamental en la independización relativa de los elementos de la actividad económica. Pero Simmel no muestra cómo el dinero lleva esto a cabo. Tal y como es planteado por Simmel, lo mismo parece ser predicable, y con tanto sentido como del dinero, de los avances en los medios de transporte, que son puramente espaciales. Efectivamente, hay una vinculación muy estrecha entre dinero y espacio, pero esta relación está sometida, en el caso del dinero-espacio, a una pura relación cuantitativa respecto a la utilidad fundamental del dinero, que es la de ejercer de lubricante de los intercambios. La misma metáfora del lubricante nos conduce al concepto que hace de mediación entre dinero y espacio por lo que respecta a este dinero-espacio descrito hasta ahora, que es el concepto de la velocidad ${ }^{\beta 1}$. El dinero acelera los intercambios; es ésta toda la relación que parece tener el dinero-espacio con el tiempo.

En cambio, la relación que el dinero tiene con el tiempo en el crédito es relativamente independiente del espacio a primera vista, o al menos del espacio tal y como lo hemos descrito hasta ahora. El dinero de un crédito se presenta a primera vista como un ejemplo de objeto social puramente tempora ${ }^{32}$. Sabemos que los análisis de Husserl en sus "Lecciones sobre la conciencia interna del tiempo" se basan en análisis sobre la percepción, y en el complejo imbricamiento entre percepción, retención, protención y rememoración. Husserl piensa en todo momento en un modelo de análisis basado en vivencias relativamente simples y "poco estratificadas" 33 , como se sigue del ejemplo mayoritariamente utilizado de la percepción de una melodía. A él le es ajena completamente la problemática de un posible "objeto social temporal". Tampoco encontramos nada parecido en los análisis de Schutz sobre las estructuras temporales del mundo de la vida como mundo social. ¿Qué es un objeto social temporal? Dilucidemos los estratos de esta expresión. Si sabemos que un objeto temporal es un objeto que para existir necesita extenderse en el tiempo (es decir, un objeto el ser del cual contiene una extensión temporal, como por ejemplo una melodía, una película, una carrera de coches o una batalla), y sabemos que un objeto social es aquel objeto que se constituye mediante la imposición de una regla constitutiva del tipo " $\mathrm{X}$ cuenta como $\mathrm{Y}$ en $\mathrm{C}{ }^{34}$, parece que, por composición, debería quedar claro lo que es un objeto social temporal: un objeto cuya existencia es una extensión temporal y que ha sido socialmente constituido. Con el adjetivo "temporal" no nos referimos simplemente a que el objeto social que aquí nos interesa en concreto (el dinero de crédito) sea "en" el tiempo; de hecho, todo objeto social lo es, en tanto que un objeto social no es otra cosa que una mera reserva de plaza para ubicar patrones de actividades ${ }^{35}$, y como tal, su temporalidad ha de verse caracterizada por la constancia de su validez ${ }^{36}$. En el sentido en el que el objeto social está subordinado al acto social, todo objeto social es temporal, al ser constituido a partir de un proceso basado en la imposición de una regla constitutiva. Pero nosotros queremos resaltar la especificidad del dinero de crédito como ejemplo dentro de los objetos sociales ins- 
titucionales. ¿Cuál es el "para qué" del dinero de crédito? El dinero de crédito está fundado en un rebasamiento de las posibilidades de mi mundo circundante cotidiano. Este rebasamiento consta de los siguientes elementos:

(a) Lo ex-puesto que quiere ser incorporado a mi mundo circundante desde su "no-poder-serlo-ahora"37.

(b) La expresión de lo ex-puesto en su forma-precio.

(c) El dinero del prestamista (de la institución bancaria) ${ }^{38}$.

(d) El tiempo futuro, o el plazo de retorno.

(e) El precio de ese tiempo (tasa de interés).

El crédito aparece desde la vivencia del límite de las posibilidades de mi mundo circundante, o bien desde la vivencia del placer de su ampliación más allá de mis posibilidades actuales ${ }^{39}$. Pero con el dinero del crédito no modalizo simplemente el ser de ningún ente: avanzo en el tiempo su modalización. Es importante tener en cuenta esta distinción: de alguna manera, yo podría tener acceso a lo ex-puesto después, en otro momento, de aquí a muchos años: en caso contrario, no se me concedería el crédito. Lo que pasa es que lo quiero (o lo necesito) ahora. El precio del dinero de crédito es el precio de ese tiempo que no estoy dispuesto a (o no puedo) esperar sin llevar a cabo esa incorporación a mi mundo. En el fondo, con el dinero de crédito no compro lo ex-puesto (si no pudiera acabar comprándolo más tarde no se me concedería el crédito); compro el tiempo en que me avanzo a su adquisición y su disfrute. Si tenemos en cuenta que el dinero que he recibido para comprar ese tiempo ha sido prestado a su vez al banco en la creación de depósitos de los cuales se obtienen beneficios, o con la función de protección, tenemos una constitución intersubjetiva de un clima de confianza en la creación de presente, o en lo que es lo mismo, en el avance y actualización del proyecto al momento presente. El mundo presente es intersubjetivamente creado a partir de la confianza en el futuro y en su posibilidad. La confianza social en el futuro permite la creación de presente. Es esta confianza la que crea el dinero de crédito, y no lo crea a partir de un stock previo de dinero ya existente. Pero el tiempo de disfrute de lo ex-puesto que no he aceptado aplazar y que he comprado ha sido creado como un objeto temporal. El tiempo de disfrute va siendo en el mundo desde lo incompleto de su pago. Por tanto, en el crédito se compra mundo, fenomenológicamente comprendido, al comprarse un tiempo del cual no dispondría ${ }^{40}$.

En ambas fuentes fenomenológicas de descripción del fenómeno monetario (tanto la exógena como la endógena), que no han sido aquí más que esbozadas muy rudimentariamente, vemos una raíz común de ambos conceptos de dinero en su referencia ontológica al concepto de mundo. Una vez superado un mero concepto formal de mundo como "la totalidad de lo ente", es imposible no ver que el concepto fenomenológico de mundo tiene que ver de manera esencial (no meramente accidental) con fenómenos como el aquí simplemente esbozado del dinero; o incluso mejor dicho, que la única manera de llevar a cabo una investigación fenomenológica sobre la esencia del mundo consiste en tener en cuenta (muy en cuenta) fenómenos que constituyen de manera radical el modo de interpretar el mundo que tenemos, como el dinero. La posibilidad de una teoría unificada sobre la significación ontológica de ambos conceptos de dinero (una teoría que derivara el concepto exógeno a partir del concepto endógeno, partiendo del elemento común a ambos de la confianza y la constitución intersubjetiva del valor), es una posibilidad a llevar a cabo en posteriores tareas. Es por ello por lo que el título de esta exposición no va más allá que el de unos "materiales" para una investigación fenomenológica del dinero, materiales que deben ir prefigurándose en la constitución de una teoria fenomenológica unificada sobre la esencia del dinero.

\section{NOTAS}

1 Es una buena expresión del renacimiento teórico de esta cuestión el volumen editado por John Smithin, What is money?, 2000.
2 Ésta es una versión bastante moderna (Bailly-Gnos, en Piégay-Rochon, 2006, p. 229) de una definición que, con pequeñas variaciones, se encuentra en prácticamente todos los manuales de teoría económica. "Unidad
Recibido: 15 de noviembre de 2007

Aceptado: 15 de enero de 2008 
de cuenta" viene a sustituir a la clásica "medida de valor", pues la "teoría del valor" se ha diluido prácticamente en la economía actual en la teoría de los precios (vid. Barber, 2005, p. 32). "Medio de pago" incluye para muchos autores la antigua función de "medio de intercambio", después de la destrucción metodológica de la "fábula del trueque" (vid. Parguez, en PiégayRochon, 2006, pp. 122 y ss.) por parte de algunos juristas, aunque algunos teóricos disocian ambas funciones (vid. Mathieu, 1990, pp. 51 y ss.). "Reserva de valor" sustituye a la que en muchos manuales aparece como "depósito de riqueza". Estas sustituciones no son indiferentes, y a veces introducen modificaciones no sólo de matiz, aunque ahora no podamos tratar estas cuestiones.

3 Algunas definiciones consideran directamente el dinero un "bien", o "cualquier bien", que asuma las cuatro funciones; por ejemplo en la definición del dinero de Menger. El concepto de "bien" es el equivalente económico del concepto de "cosa", ya que la definición de "bien" de los manuales de economía es "cualquier cosa susceptible de satisfacer una necesidad". Según Menger, hay unas condiciones empíricas determinadas que favorecen la elección de una cosa concreta como dinero respecto a otras: su durabilidad, portabilidad, divisibilidad, etc., son condiciones fisicas que condicionan la mayor liquidez (Absatzfähigkeit) de una cosa, y por tanto, facilitan su elección como dinero.

4 Con el concepto de "algo" o de "alguna cosa" no nos referimos estrictamente a una cosa "física", entendiendo por ésta una cosa que se constituye en dinero en base a sus propiedades empíricas, a pesar de que la teoría cuantitativa del dinero apunte a una génesis de todas las formas de dinero en el dinero-mercancía. Para lo esencial del concepto de "dinero exógeno", puede entenderse por éste tanto el dinero-mercancía, entendido como una cosa física por sus propiedades, como un simple objeto social. Entendemos por "objeto social" aquel objeto constituido mediante la imposición de una regla constitutiva del tipo "X cuenta como $Y$ en $C$ ", donde " $X$ " es un objeto físico, la locución "cuenta como" nombra un rasgo de la imposición de un status al que se vincula una función por medio de la intencionalidad colectiva, Y asigna un estatus no poseido previamente por el objeto $X$ en virtud de sus propiedades físicas, y $\mathrm{C}$ remite al contexto (para el status ontológico de los objetos sociales, vid. Searle, 1995, p. 43). Asi, en el caso del dinero fiduciario, está claro que el valor de un billete no reside en sus propiedades físicas específicas, sino en la declaración por parte del gobierno del Estado, mediante un acto institucionalizador performativo, de que eso es dinero. No obstante, ese billete es una "cosa". Lo mismo vale para el dinero electrónico, que no es otra cosa, físicamente considerado, que números en discos de ordenador. Searle sostiene que los objetos sociales, plenamente ligados a los actos sociales, deben con todo tener siempre alguna forma física que está en su base, independientemente de cómo se le aplique después a esta forma su regla constitutiva (vid. Searle, 1995, p. 55).

5 Esta distinción está ya anunciada en Aristóteles (Política, I, 8-10), y es considerada por Schumpeter "la raíz de cualquier trabajo analítico en el campo del dinero" (vid. Schumpeter, 1995, p. 100).
6 Heidegger, SuZ, 1993, p. 68.

7 Evidentemente, toda matización será poca respecto a la especificidad de este nuevo "para" que constituye el dinero respecto a su ser anterior como otra cosa. Los argumentos de Hammond para diferenciar radicalmente el modo de ser del dinero del modo de ser del útil parten de una interpretación muy restrictiva del segundo, que lo restringe prácticamente al ámbito de lo manual-operacional (vid. Hammond, 2001, pp. 37 y ss.). En este sentido, Hammond se deja condicionar en exceso por la dinámica de los ejemplos heideggerianos en Ser y Tiempo.

8 Vid. Ingham, en Smithin, 2000, p. 17.

9 Vid. Bailly y Gnos, en Piégay-Rochon, 2006, p. 220.

10 lbid., p. 221.

11 Vid. Smithin, 2000; también Ingham, 2005. Evidentemente, que el problema se haya decantado hacia un tratamiento teórico u ontológico no excluye en ningún momento que el problema esté desconectado de multitud de implicaciones prácticas, incluso políticas. En este caso, estas derivaciones no deben ser tenidas en cuenta; han de ser puestas entre paréntesis en el intento de una descripción fenomenológica ausente de presupuestos del fenómeno del dinero.

12 Vid. Basil J. Moore, en Piégay-Rochon, 2006.

13 Vid. E. Husserl, Philosophie als strenge Wissenschaft, 1965, p. 9.

14 Vid. Husserl, Ideen I, 1, Hua III, par. [24] (trad. de Gaos, p. 58).

15 Cabe descartar de entrada cualquier similitud entre metodología fenomenológica y cualquier intento de fundamentación microeconómica de postulados teóricos generales. La adopción fenomenológica de la perspectiva de descripción en 
primera persona, como uno de los rasgos esenciales de su metodología (vid. Hua III, p. 48), poco o nada tiene que ver con el sentido de querer partir desde la consideración de los agentes de los procesos económicos considerados individualmente. La fenomenología se ocupa de los actos, entendidos como vivencias de conciencia, no de "individuos" respecto a las decisiones o elecciones de los cuales se van a ejercer de manera inmediata formalizaciones que fijen los axiomas de la teoría del consumidor. Ya el mismo concepto de "consumidor" predetermina la descripción de lo que, para el fenomenólogo, no es otra cosa que una persona que compra, y cuyas vivencias pueden ser descritas. La fenomenología no es más microeconómica que macroeconómica, en tanto que la noción de "individuo" de la microeconomía no está ontológicamente fundada, y poco o nada tiene que ver con la descripción de las vivencias de conciencia del mundo de la vida. Para la distinción metodológica entre el concepto naturalista de "individualidad" y el concepto fenomenológico de la individualidad, vid. Ideen II, Hua IV, pp. 298 y ss.

16 Heidegger, SuZ, 1993, par. [22]: "Das 'zur Hand' Seiende hat je eine verschiedene Nähe, die nicht durch Ausmessen von Abständen festgelegt ist" (p. 102).

17 Heidegger entiende por la "no familiaridad" (Unvertrautheit) lo "conocido" (gekannt) pero respecto a lo cual no sabemos habérnoslas; el ejemplo es el de una persona que entra en un taller de un zapatero: podrá reconocer algunas herramientas, pero éstas no son para él, ciertamente, "a la mano". No son "extrañas", pero son, de algún modo, no familiares
(GA 24, 1975, p. 432). Piénsese en el funcionamiento de un coche (embrague, palanca de marchas, etc.) para una persona que no tiene el carnet de conducir, por ejemplo. En cambio, para un aborigen del amazonas, las cosas de un taller de zapatero, se presentan según el modo de ser de lo nuevo (Neue), en el sentido de lo extraño, de aquello respecto a lo cual no sabemos en qué sentido podría llegar a ser alguna vez "a la mano" para alguien (GA 24, 1975, p. 442).

18 SuZ, 1993, par. [18], p. 84.

19 La primera parte de esta precisa aunque rocambolesca expresión (des-alejados) refiere a la parte de la cosa ex-puesta que esta cosa comparte con las cosas "a la mano", en el sentido de cosas que me salen inmediatamente al encuentro. La mercancía es des-alejada desde las condiciones peculiares de des-alejamiento que provienen de la zona (tienda) en la que se encuentra, y que fijan sus condiciones de aparición. La segunda parte de la expresión (en su alejamiento) refiere a la imposibilidad de esa cosa que me viene inmediatamente al encuentro de ser utilizada como cosa "a la mano"; pero esta imposibilidad (esto es importante) le pertenece a la cosa misma desde su modo de aparición; la cosa no me aparece como "a la mano"; la cosa "se me sustrae"; la cosa me viene al encuentro en su "no poder ser-me a la mano" a no ser que pague. No es una cosa "a la mano" que no puede ser utilizada por alguna razón, como algún funcionamiento defectuoso u otra cuestión. El ejemplo de la mercancía no tiene que ver nada con el ejemplo de un banco del parque en el que no me puedo sentar porque está "recién pintado". El banco del parque, sobre el que cuelga el cartel de "recién pintado", no está efectivamente "ex-puesto", sino que sigue estando, en todo momento, colocado. Ese banco sigue estando en "su" lugar. Su acceso como cosa "a la mano" se ha visto suspendido, pero en todo momento el banco es una cosa "a la mano" que se me muestra en su imposibilidad accidental de ser usada. Esto lo demuestra el hecho de que, en el caso de que no viera el cartel, me habría sentado efectivamente en el banco (para darme cuenta posteriormente, para mi desgracia, de que había cometido un error). Nada de esto sucede con la mercancía; la mercancía lleva, en sus propias condiciones de manifestación, su sustraerse como "a la mano", sin ningún otro condicionante "externo" que sus propias condiciones de aparición en la misma zona de la tienda. Nadie cogería una mercancía (sin la mediación del dinero; es decir, sin pagar) por "error"; y no hace falta pensar mucho para decidir qué consideración tendria para la seguridad de la tienda alguien que argumentara que había cogido algo "por error", o por no saber que estaba "ex-puesto". Por otro lado, algo que fuera "a la mano" pero que no pudiera ser utilizado por algún hecho concreto (como por no ser "mío"), no se manifestaría sobre un maniquí, sino que su acceso se presentaría como para ser usado inmediatamente. En el acto de compra no se manifiesta nunca inmediatamente la cuestión de la "propiedad" como tal; el acto de "comprar" no es vivido como un "intercambio de propiedades" (tampoco de "posesiones", pues el vendedor no tiene las mercancias "en sus manos", sino que éstas residen en el espacio "fenomenológicamente neutral" de la ex-posición); de hecho, cuando compro algo, no sé exactamente muy 
bien "a quién" se lo compro. El acto de compra como acto jurídico sólo se manifiesta como un acto reflexivo posterior al hecho de la compra como tal. El paso de la fenomenología del acto de compra como tal al acto de compra como acto jurídico-teórico se analizará en posteriores desarrollos de nuestra teoría.

20 Este "lugar" del que viene la mercancía, que no es, en el fondo, ningún "lugar" (y de aquí viene la categoría de la "producción"), será tematizado posteriormente en una fenomenología genética de los actos de compra. El "mirar lo que está ex-puesto" no es el "contemplar teórico", pero tampoco es el simple "mirar" el mundo circundante exterior a la zona de la tienda.

21 Las cosas ex-puestas están des-colocadas respecto a su comprensión inmediata como "a la mano", dado que han sido arrancadas de totalidad respeccional alguna concretada en la cual pudieran funcionar como "a la mano". Pero esto no quiere decir que estén des-colocadas respecto a totalidad respeccional alguna dada, como si las hubieran sacado "literalmente" de sus condiciones "a la mano". La manifestación de la cosa en la espacialidad de la ex-posición es una manifestación originaria. La camisa que veo sobre el maniquí no ha sido sacada de un cuerpo humano para ser ex-puesta ahí enfrente; el coche del concesionario no ha sido sacado de la carretera para ser ex-puesto ahí (si es de primera mano, claro está). El pan ex-puesto en las cajas de la panadería no ha sido sacado de la mesa para ser ex-puesto ahí. El "no ser a la mano" de la mercancía no proviene de que se le haya "sustraído" a éstas mercancias concretas, ex-puestas ahí enfrente, algún anterior "ser a la mano" desde el cual hubieran es- tado siendo. Desde la constatación de este hecho, cabe llevar a término dos consideraciones importantes. Primera: ¿cómo puede una cosa que nunca ha estado colocada en totalidad respeccional "a la mano" alguna manifestarse como "des-colocada"? Esta pregunta nos conducirá al papel que jugará la mercancía como idea: la mercancía no se presenta des-colocada respecto a totalidad respeccional alguna anterior, sino que la mercancia ha sido pensada para que se muestre como des-colocada respecto a $m i$ totalidad respeccional "a la mano" concreta como comprador, totalidad respeccional concreta que ha tenido, pues, que ser pensada hipotéticamente por el productor de la mercancía. Segunda: la cosa ha sido hecha para ser ex-puesta; eso nos conduce a la categoría económica de la producción como categoría generadora de la espacialidad de la exposición. Estas consideraciones serán objeto de análisis en una posterior fenomenología genética de los actos de compra.

22 No sólo de la espacialidad; habrá de ser tenido en cuenta el aspecto fundamental de la temporalidad de la mercancía. De la vivencia humana de la temporalidad proviene la segunda vivencia fundamental del dinero, constituidora de la endogeneidad: el crédito. La conexión entre los cambios en la comprensión de la espacio-temporalidad y los fenómenos económicos (fundamentalmente el dinero) ha sido señalada con acierto por Simmel, aunque es ganada desde categorías no fenomenológicas (vid. Simmel, GA 6, pp. 448 y ss.); el concepto sociológico de "desanclaje" es reconocido por Giddens como extraido a partir de la investigación de Simmel (vid. Giddens, 1998, p. 23).
23 Sobre la crítica del uso de expresiones de totalidad en las estructuras heideggerianas del análisis de la circunmundanidad, vid. Tugendhat, 2001, pp. 109 y ss. Cuando hablamos de "totalidad de conformidad" nos referimos a una totalidad que desemboca estructuralmente en el Dasein, y por tanto, de una totalidad de conformidad que tiene al dasein como "centro". Por eso, hablamos de "totalidad de conformidad" de mi mundo a la mano.

24 No descartamos un contenido de verdad en la famosa tesis sobre la confusión substancial al ser humano entre el "ser" y el "tener" (vid. Fromm, 1978, pp. 77 y ss.); tan sólo discutimos que el fundamento ontológico del deseo humano de "tener muchas cosas" recaiga en esta confusión. Básicamente porque el contenido de la tesis de la confusión no ha procedido previamente a una descripción fenomenológica detallada de lo que significan los conceptos de "ser" y "tener" en la órbita de nuestros problemas, como por ejemplo la que hemos llevado a cabo nosotros con el "comprar". La tesis de la confusión recae en el ámbito de la descripción de la vida psicológica subjetiva del ser humano desde cierta denuncia de una "pérdida de sentido", y la circunscribe al ámbito de la terapéutica. Este punto de partida de la tesis de la confusión, que adopta desde sus raíces más profundas una perspectiva terapéutica, condiciona todo el desarrollo posterior de sus descripciones sobre la vida psicológica del sujeto en la sociedad moderna en la búsqueda de la felicidad, y sus desarrollos sólo serían aplicables con generalidad aceptando la tesis de que todos estamos enfermos (vid. Fromm, 1992, pp. 18 y ss.), tesis que, no sien- 
do descartable de entrada, requiere de una fundamentación más precisa por parte del que la sostiene.

250 lo que en teoría económica se denomina "poder de compra" del dinero. En las dimensiones del presente ensayo no podemos explicar porqué el dinero sólo puede constituirse como modalizador cuantificando las mercancías, la relación entre el dinero y el número, entre la mercancía y su manifestación en su forma-precio, o lo que es lo mismo, una teoría genética del "dinero de cuenta", etc. Todos estos temas se incluirian dentro de la descripción fenomenológica de lo que hemos llamado dinero-espacio, que es el dinero de la compra, o del intercambio, pero aquí no podemos llevar a cabo más que esta aproximación a lo que el dinero "hace": el acto de compra, teniendo que relegar de momento aspectos analíticos esenciales referentes a cómo el dinero hace lo que hace.

26 Cabe diferenciar y deslindar muy estrictamente ambos conceptos, porque si no corremos el riesgo de proyectar acríticamente la validez de la teoría economía clásica a cualquier situación histórica. Según K. Polanyi, los mayas, los incas, Micenas, la Europa medieval y las islas Trobiand serian ejemplos de situaciones históricas con mercado en el primer sentido pero sin mercado en el segundo sentido (vid. Aubet, 2007, pp. 43 y ss.)

27 Evidentemente, la definición vale para los casos originarios y más concretos. El directivo de una multinacional que compra acciones de otra empresa no compra para esto. Estas otras formas de compra escapan a la definición fenomenológica de dinero, porque están montadas sobre las estructuras más fundamentales susceptibles de descripción fenomenológica. En los casos más abstractos, la compra sí que puede entenderse como un simple cambio de propiedades. El concepto de "propiedad" pasa a ser el concepto rector, pues está claro que nadie incorpora "acciones" (partes abstractas) a su mundo entorno.

28 Esto es válido tanto para las materias primeras, que me quedan lejos, como para los stocks de objetos producidos en las fábricas, la diferencia de distancia respecto a los cuales sólo es cuantitativa.

29 Vid. Max Weber, La ética protestante y el espiritu del capitalismo, Istmo, 1998, p. 106

30 Vid. Georg Simmel, Philosophie des Geldes, GA Band 6, Suhrkamp, 1989, p. 448. La traducción castellana es de Ramón García, ed. Comares, 2003, p. 414. Los ejemplos de Simmel refieren a agentes implicados en la producción, pero son igualmente aplicables a la relación entre comprador y vendedor.

31 Hay que estar alerta con conceptos como el de "velocidad de circulación" del dinero, la determinación del cual es fundamental en la ecuación cuantitativa de Fisher, porque en el fondo su expresión obedece también a una metáfora. No se trata de la derivada del espacio respecto al tiempo que el dinero emplea en recorrerlo, sino simplemente de la frecuencia, estadisticamente determinable, con que el dinero es gastado. "La velocidad monetaria es simplemente el volumen medio de transacciones por unidad de moneda, aun cuando algunas unidades no se gasten en absoluto" (vid. Mathieu, 1989, p. 118).

32 E. Husserl, Hua X, p. 23. De la trad. cast: "Por objetos temporales en sentido especial entendemos objetos que no solamente son unidades en el tiempo, sino que también contienen en sí la extensión en el tiempo", vid. Lecciones, trad. de Agustín Serrano de Haro, 2002, p. 45.

33 Aunque vistos los estratos encontrables fenomenológicamente en la más simple de las vivencias, como por ejemplo escuchar una melodía, parece prematuro hablar en general de "vivencias poco estratificadas".

34 Vid. la nota 5 para ampliar esta definición de "objeto social".

35 Vid. Searle, 1995, p. 57: "What we think of as social objects, such as governments, money, and universities, are in fact just placeholders for patterns of activities".

36 Searle afirma que es propio de la temporalidad de los objetos sociales la constancia de su validez, fruto de que precisamente en los objetos sociales el carácter objetual está subordinado al carácter procesual de su constitución. El acto social tiene primacia sobre el objeto social, porque es el primero el que constituye al segundo. Eso explica que los objetos sociales no se desgasten. Un billete de veinte euros es una constante posibilidad de pagar algo (el desgaste de un billete físico no es el desgaste del objeto social, sino de su soporte). Esta constancia indefinida de la validez de la regla constitutiva permite diferenciar la constitución de reglas institucionales de los juegos de la constitución de reglas en la vida social: una partida de billar informal, con todas sus reglas, no tiene consecuencias más allá de que se acabe la partida (precisamente, cuando pasa a tenerlas, como en una partida de billar profesional, eso ya no es un mero juego, sino un negocio u otro tipo de acto social); las consecuencias de una compra-venta, en cambio, se sitúan en el eje de los hechos que condiciona el acontecer del futuro, y

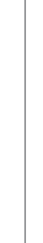


sus reglas no pierden validez a partir de un momento dado; vid. Searle, 1995, p. 36.

37 En el carácter de este ex-puesto pueden ser válidas con carácter general nuestras descripciones anteriores sobre la ex-posición de la mercancía y su correlato en el dinero-espacio, pero en el bien entendido que amplian mucho sus restricciones espaciales. Lo ex-puesto puede ser algo que he visto tan sólo en un anuncio publicitario televisivo, y nunca en condiciones espaciales físicas (recuérdese el carácter de la mercancia también como "idea"; vid. nota 22). Asimismo, la extensión de los modos de la espacialidad en, por ejemplo, la visita a una casa para comprarla, son fruto de una ampliación considerable del concepto de ex-posición que hemos llevado a cabo en nuestras descripciones anteriores: en su abstracción y generalización, todo mi espacio circundante puede operar como espacio ex-puesto (recuérdese que para nosotros ex-poner no es poner "delante", sino poner "fuera" del espacio de lo a la mano. Cuando visito una casa para saber si puede interesarme, evidentemente, todo el espacio, y mi moverme a través de él, funciona como un espacio expuesto). El tema del pago de servicios requiere de una interpretación fenomenológica del tema que le da fundamento, el trabajo, y de su relación con el dinero, de la que aquí no podemos hablar. Con todo, está claro que, a partir de sus formas más primarias y concretas, el sistema de mercado evoluciona históricamente hasta considerar tanto la tierra, como la vivienda, como el trabajo, como mercancías, y a ahogar a estos fenómenos en la uniformización de las características descriptivas de la mercancía, por mucho que desde una teoría fenomenológica pueda discutirse con plena legitimidad las deficiencias de esta homogeneización.

38 Este dinero, a su vez, proviene del préstamo de otros clientes, que crean depósitos a cambio de intereses. Esto nos introduciría en la teoría monetaria del circuito, que queda más allá de nuestra presente descripción. Para una buena introducción a la teoría del circuito, con especial referencia a su relación con el concepto endógeno del dinero, vid. Louis-Philippe Rochon, On money and endogenous money: post keynesian and circulation approaches, en Rochon, 2003, pp. 115 y ss.

39 Puede ser interesante el tema de la distinción entre el crédito por necesidad y el crédito de consumo por placer, pero en nuestra descripción formal actual esta distinción puede ser pasada por alto: en ambos casos se da un rebasamiento temporal de los límites del actual mundo circundante.

40 En esta frase, tanto el verbo "comprar" como la palabra "mundo" deben entenderse en su fundamento fenomenológico; es decir: "comprar" en tanto que modalizar lo ex-puesto en a la mano, y "mundo" en tanto que totalidad de remisión y de conformidad de lo ente respecto a mí.

\section{BIBLIOGRAFÍA}

Aubet, M. ${ }^{a}$ Eugenia (2007): Comercio y colonialismo en el Próximo Oriente Antiguo, Ed. Bellaterra Arqueología, Barcelona.

Barber, William (2005): Historia del pensamiento económico, Alianza Universidad, Madrid.

Fromm, Erich (1992): Psicoanálisis de la sociedad contemporánea, FCE, México.
Giddens, Anthony (1998): Consecuencias de la modernidad, Alianza Universidad, Madrid.

Hammond, Mark (2001): A heideggerian phenomenological investigation of money, Edwin Mellen Press, Nueva York.

Heidegger, Martin (1993): Sein und Zeit, Max Niemeyer, Tubinga.

- (1975): Grundprobleme der Phänomenologie, Gesamtausgabe Band 24, Vittorio Klostermann, Frankfurt a.M.

Husserl, Edmund (1965): Philosophie als strenge Wissenschaft, Vittorio Klostermann, Frankfurt a.M.

- (1950): Ideen zu einer reinen Phänomenologie und phänomenologischen Philosophie. Erstes Buch, Husserliana Band III, Martinus Nijhoff.

- (1969): Zur Phänomenologie des inneren Zeitbewusstesens, Husserliana Band $X$, Martinus Nijhoff.

Ingham, Geoffrey (2005): The Nature of Money, Polity Press, Cambridge.

Mathieu, Vittorio (1990): Filosofía del dinero, Rialp, Madrid.

Piégay, Pierre (ed.) (2006): Teorías monetarias poskeynesianas, Akal, Madrid.

Rochon, Louis-Philippe (ed.) (2003): Modern theories of money. The nature and role of money in capitalist economies, Edwar Elgar, Cheltenham.

Schumpeter, Joseph A. (1995): Historia del análisis económico, Ariel, Barcelona.

Searle, John R. (1995): The construction of social reality, Penguin, Londres.

Simmel, Georg (1989): Philosophie des Geldes, Gesamtausgabe Band 6, Suhrkamp, Frankfurt a. M.

Smithin, John (ed.) (2000): What is money?, Routledge International Studies in Money and Banking, Nueva York.

Tugendhat, Ernst (2001): Aufsätze 19922000, Suhrkamp, Frankfurt a.M.

Weber, Max (1998): La ética protestante y el espíritu del capitalismo, Istmo, Barcelona. 